\title{
Non-enzymatic covalent modifications: a new link between metabolism and epigenetics
}

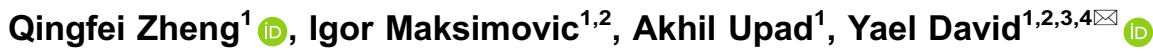 \\ ${ }^{1}$ Chemical Biology Program, Memorial Sloan Kettering Cancer Center, New York, NY 10065, USA \\ 2 Tri-Institutional PhD Program in Chemical Biology, New York, NY 10065, USA \\ ${ }^{3}$ Department of Pharmacology, Weill Cornell Medicine, New York, NY 10065, USA \\ ${ }^{4}$ Department of Physiology, Biophysics and Systems Biology, Weill Cornell Medicine, New York, NY 10065, USA \\ $\triangle$ Correspondence: davidshy@mskcc.org (Y. David) \\ Received March 10, 2020 Accepted April 2, 2020
}

\begin{abstract}
Epigenetic modifications, including those on DNA and histones, have been shown to regulate cellular metabolism by controlling expression of enzymes involved in the corresponding metabolic pathways. In turn, metabolic flux influences epigenetic regulation by affecting the biosynthetic balance of enzyme cofactors or donors for certain chromatin modifications. Recently, non-enzymatic covalent modifications (NECMs) by chemically reactive metabolites have been reported to manipulate chromatin architecture and gene transcription through multiple mechanisms. Here, we summarize these recent advances in the identification and characterization of NECMs on nucleic acids, histones, and transcription factors, providing an additional mechanistic link between metabolism and epigenetics.
\end{abstract}

KEYWORDS epigenetics, metabolism, non-enzymatic modification, chromatin, human disease

\section{INTRODUCTION}

The genetic information of eukaryotes and archaea is packaged in the nucleus as a dynamic nucleoprotein chromatin complex that not only stores it efficiently but also allows it to remain readily accessible (Ammar et al., 2012). At the molecular level, the DNA strand wraps approximately 1.65 times around a histone octamer complex, which itself consists of two copies of each of the four core histones (i.e., $\mathrm{H} 2 \mathrm{~A}, \mathrm{H} 2 \mathrm{~B}, \mathrm{H} 3$, and $\mathrm{H} 4$ ) forming a nucleosome, the fundamental unit of chromatin (McGinty and Tan, 2015). Histones contain an unusually high representation of positively charged lysine and arginine residues that electrostatically interact with the negatively charged phosphodiester backbone of DNA and stabilize the nucleosome core particle (Erler et al., 2014). To regulate the interactions between histones and nucleosomal DNA or transcription factors (TFs), the histone residue side-chains are modified, typically through enzyme-mediated incorporation of metabolite molecules or cofactors, such as acetylation and methylation, and even full proteins, such as ubiquitination and sumoylation (Bannister and Kouzarides, 2011). The resulting plethora of modifications regulate cellular physiology by directly impacting chromatin structure and the pattern of gene expression, including essential enzymes involved in metabolic pathways (Janke et al., 2015). Thereafter, these enzymes can directly influence the epigenetic state of DNA, RNA and histones by balancing the biosynthesis of co-factors that serve as the co-substrates and donors for covalent modifications (e.g., S-adenosyl methionine for methylation and acyl-coenzyme A for acylation), thereby propagating the feedback loop (Fig. 1) (Rinschen et al., 2019).

Beyond enzyme-mediated epigenetic modifications, chemically reactive metabolites have been shown to directly modify nucleotides and histones via spontaneous non-enzymatic reactions (Zheng et al., 2019). Unlike canonical post-translational modifications (PTMs), non-enzymatic covalent modifications (NECMs) accumulate over time and are much more dependent on the cellular microenvironment (Harmel and Fiedler, 2018). Although metabolite-induced NECMs have lower selectivity than enzymatic modifications, histone proteins are particularly susceptible to NECMs due to their long half-lives within cells and disordered, nucleophilic tails (Commerford et al., 1982). Indeed, NECMs have emerged as a new family of chromatin modifications with direct effect on its structure and function. These NECMs have been identified on DNA, RNA and histones and are 


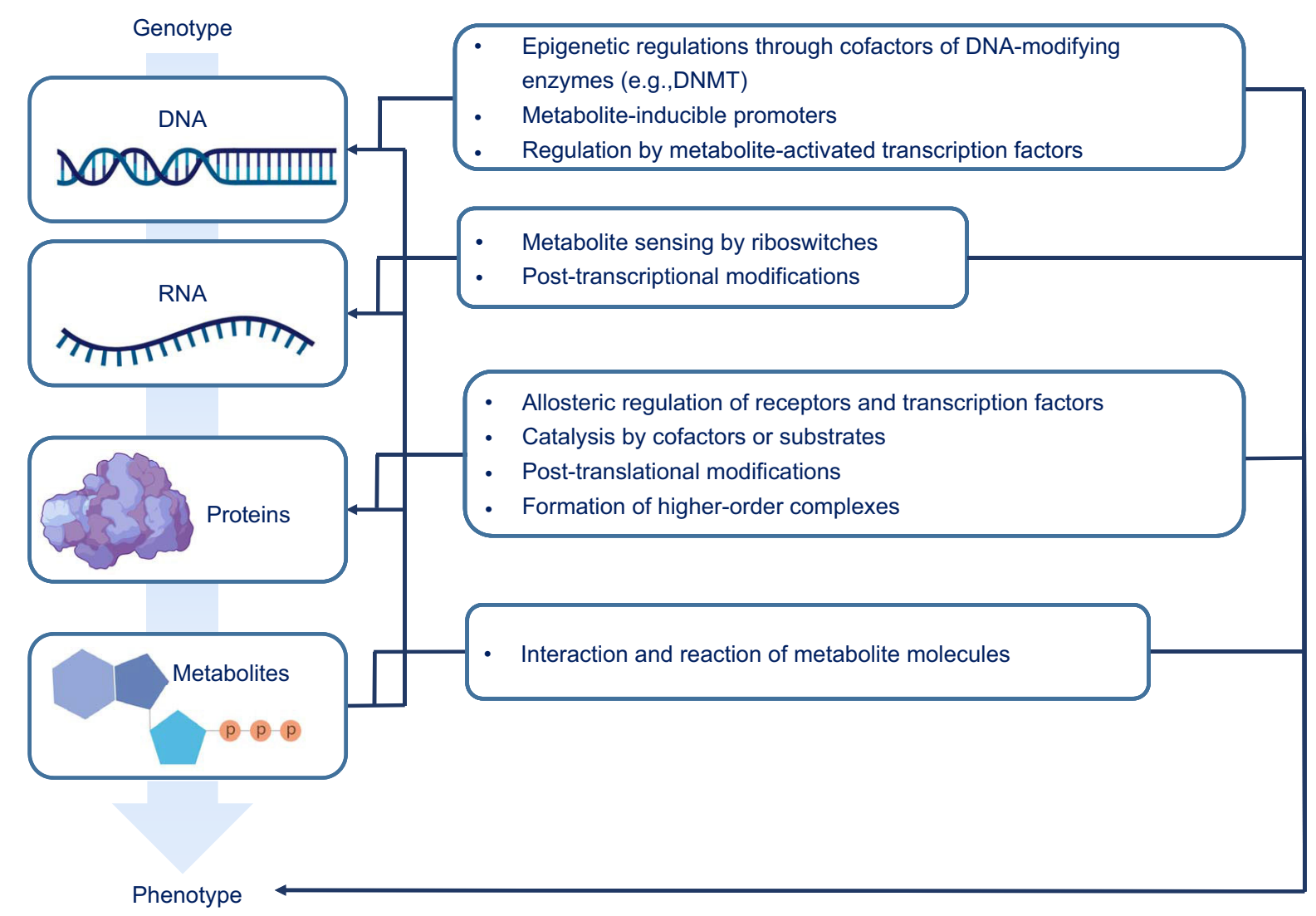

Figure 1. The multi-level crosstalk between metabolism and epigenetic regulation of cellular transcription.

implicated in disease states; however, their pathophysiological mechanisms, particularly, the presence of any causative relationships, remain elusive (Zheng et al., 2019). In this review, we summarize recent advances in NECM characterization, categorize them based on chemical reactions, and discuss their corresponding functions in disease progression, subsequently providing new perspectives regarding the link between metabolism, diet, and epigenetic regulation.

\section{GLYCATION}

The Maillard reaction is well known in food chemistry, where aldehyde groups of reducing sugars, most of which are aldoses (glucose, ribose, deoxyribose, fucose, glyceraldehyde etc.), react non-enzymatically with the nucleophilic groups (e.g., amine, sulfydryl and hydroxyl) of biomacromolecules such as DNA, RNA and proteins, in a process known as glycation (Hellwig and Henle, 2014). Unlike O-linked glycosylation which is regulated by O-GIcNAc transferase and O-GICNAcase, glycation donors do not require activation by uridine diphosphate (UDP) and their modification sites on proteins are primarily lysine residues instead of serine, threonine or tyrosine (Fig. 2A) (Spiro, 2002). The glycation process is relatively slow as once the initial Schiff base is formed (Fig. 2B), a rate-limiting isomerization step is required to drive the cascade forward (Hellwig and Henle, 2014). However, upon the completion of this hydride shift, an array of rearrangement products is rapidly generated, ultimately forming chemically stable advanced glycation end products (AGEs) (Singh et al., 2001).

Besides the canonical reducing monosaccharides that can be assimilated through nutrition, several sugar metabolism intermediates are also spawned from glycation pathways within cells. For instance, methylglyoxal (MGO; $\mathrm{C}_{3} \mathrm{H}_{4} \mathrm{O}_{2}$ ) is a reactive dicarbonyl sugar metabolite that spontaneously reacts with primary amine and guanidino groups (Fig. 2C) (Schalkwijk and Stehouwer, 2020). While MGO is primarily generated as a byproduct during glycolysis (Allaman et al., 2015), it can also be biosynthesized from aminoacetone by a semicarbazide-sensitive amine oxidase (SSAO) (Obata, 2006) or oxidized from acetone by a P450 enzyme, CYP2E1 (Bondoc et al., 1999) (Fig. 2C). MGO is enriched in metabolically dysfunctional cells that overly rely 
on glycolysis for energy, resulting in the buildup of the glycolytic intermediates glyceraldehyde-3-phosphate (GA3P) and dihydroxyacetone phosphate (DHAP), which ultimately fragment into MGO (Allaman et al., 2015). Other types of aldehyde-bearing metabolites (e.g., ascorbic acid, dopegal, formaldehyde, 5-formylcytosine, and isolevuglandins) also form NECMs on proteins via the same Maillard chemistry (Fig. 2D and 2E) (Linetsky et al., 2007; Szende and Tyihák, 2010; May-Zhang et al., 2018; Raiber et al., 2018; Wanner et al., 2020).

\section{DNA and RNA glycation}

Previous studies have demonstrated that guanine residues in DNA and RNA can undergo methylglyoxal glycation (Fig. 3A), thereby inducing DNA and RNA damage (Jaramillo et al., 2017; Shuck et al., 2018). The MGO-induced DNA damage product, $\mathrm{N}^{2}$-carboxyethyl-2'-deoxyguanosine (CEdG) (Fig. 3A), is a significant DNA AGE in human cells ( 1 in $107 \mathrm{dG}$ ) (Synold et al., 2008). CEdG has been reported to be mutagenic in human cells and contributes to genomic instability, while this DNA damage has few corresponding repair pathways (Wuenschell et al., 2010; Tamae et al., 2011). Based on its reactivity against RNA (Mitchell et al., 2018), MGO derivatives have been applied as RNA structural probes of guanine base-pairing for transcriptomewide RNA structure mapping (Weng et al., 2020). Finally, MGO-induced DNA/RNA glycation might be an important biomarker in human diseases such as diabetes and cancer (Jaramillo et al., 2017), however, there remains a lack of efficient sequencing methods reported for global profiling of DNA/RNA glycation sites.

\section{Histone glycation}

Histones are primary glycation substrates because of their long half-lives and abundant lysine (Lys) and arginine (Arg) residues (Zheng et al., 2019). While different types of aldoseinduced histone glycation have been observed through both in vitro and in vivo experiments for decades (Talasz et al., 2002), an epigenetic link and working model in disease states has only been recently reported (Zheng et al., 2019). Specifically, histone glycation was found to induce epigenetic dysregulation through three distinct mechanisms: 1) competition with essential enzymatic PTMs for sites (e.g., glycation adducts replace $\mathrm{H} 3 \mathrm{~K} 4 \mathrm{me} 3$ and $\mathrm{H} 3 \mathrm{R} 8 \mathrm{me} 2), 2$ ) changing the charge states of histone tails and subsequently affecting the compaction state of the fiber, and 3) altering three-dimensional chromatin architecture by inducing both histone-histone and histone-DNA crosslinking (Zheng et al., 2019). The epigenetic impacts of histone glycation were shown to be dependent on sugar concentration and exposure time. These results were summarized in a two-stage histone MGO-glycation damage model, which proposed that the initial acute exposure stage introduces a low number of scattered adducts induces chromatin 'relaxation', transitions to fiber compaction following chronic exposure due to AGE and cross-link formation (Fig. 3B) (Zheng et al., 2019). The two-stage model intuitively suggests that histone glycation serves as a double-edged sword in gene transcription, where the compaction of chromatin is dynamically manipulated first by spontaneous rearrangement and then by crosslinking of glycation products. Despite their well-documented occurrence and effects, the detailed structures of histone AGEs are still poorly understood because of their highly dynamic nature, chemical complexity and low abundance. The most prominently used methods for characterization of histone glycation are mass spectrometry and antibody-based immunological assays (Galligan et al., 2018). However, new chemical tools (Zheng et al., 2020) and proteomics methods (Chen et al., 2019), capable of tracking or discerning specific adducts, are currently being developed to further understand the biochemical mechanisms of these events.

\section{Transcription factor glycation}

The oncoprotein, nuclear factor erythroid 2-related factor 2 (NRF2), is a master regulator of the antioxidant response pathway and serves as a key pathological transcription factor in diseases such as cancer and atherosclerosis (Kawai et al., 2011). NRF2 exercises its functions in association with Kelch ECH associating protein 1 (KEAP1), in what is designated the KEAP1-NRF2 pathway (Kansanen et al., 2013). KEAP1 is a substrate adaptor protein for a CUL3-dependent E3 ubiquitin ligase complex which targets NRF2 for ubiquitination and subsequent degradation by the 26S proteasome (Zhang et al., 2004). PTMs on KEAP1, as well as oxidative and electrophilic stress, can reduce its ubiquitination activity, resulting in the cellular accumulation and activation of NRF2 (Keum, 2011; Kansanen et al., 2013). This in turn initiates the transcription of cytoprotective genes at antioxidant-response element loci.

Two recent studies demonstrated that both KEAP1 (Bollong et al., 2018) and NRF2 (Sanghvi et al., 2019) undergo glycation under physiologically relevant metabolic stress. The glycation of multiple lysine residues of NRF2 inhibits its oncogenic function, which is reversed by the deglycase activity of fructosamine-3-kinase (FN3K, Fig. 3C) (Sanghvi et al., 2019). Moreover, MGO selectively modifies KEAP1 to form a methylimidazole crosslink between proximal cysteine and arginine residues, resulting in the covalent dimerization of KEAP1 as well as the accumulation of NRF2 once more (Fig. 3C) (Bollong et al., 2018). These findings illustrate that sugar molecules can influence epigenetic events through glycation of transcription factors and/or their associated regulatory proteins.

\section{Regulatory mechanisms of glycation}

Since excessive glycation forms crosslinks within chromatin, which blocks transcription, distinct pathways have evolved to 


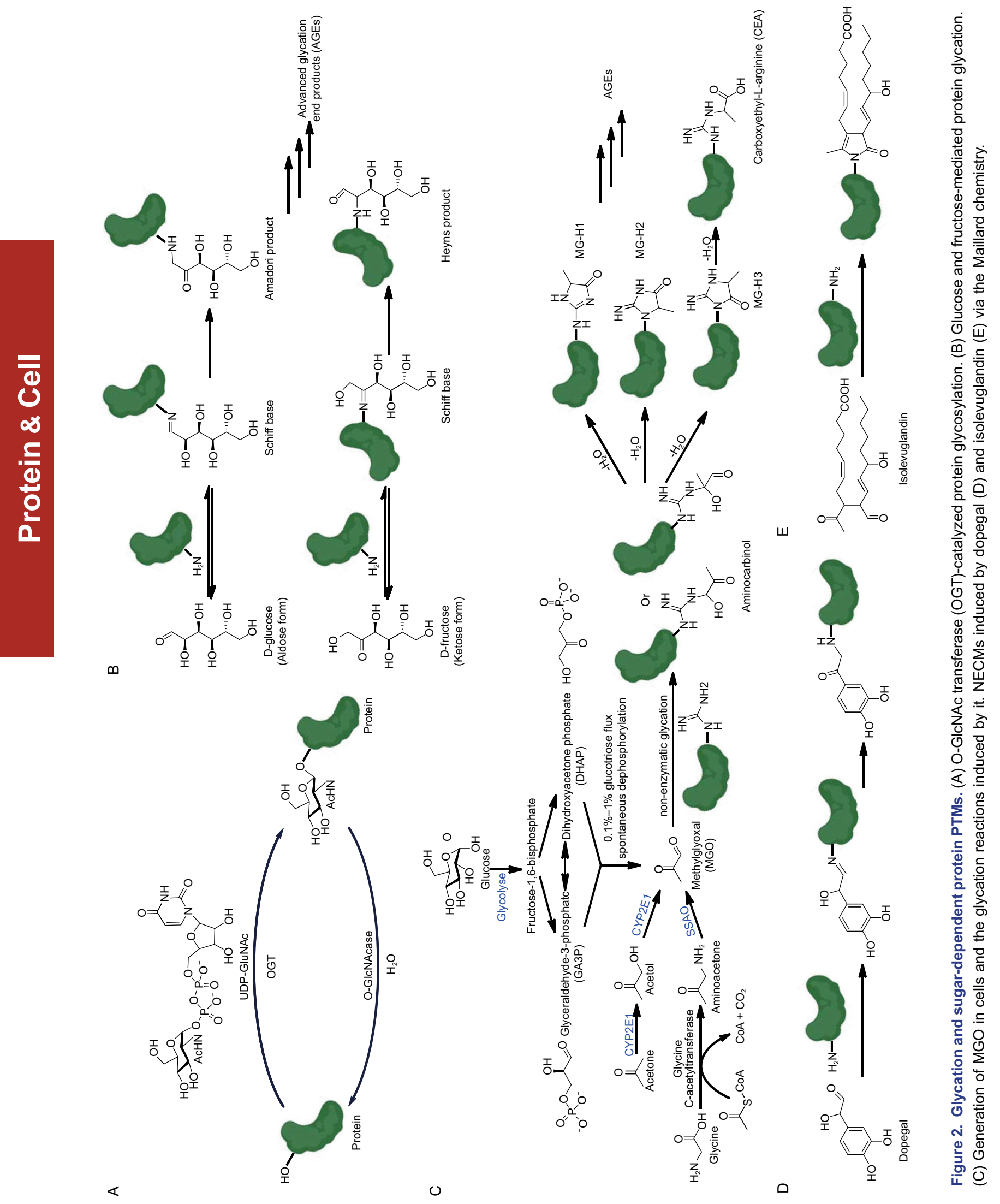




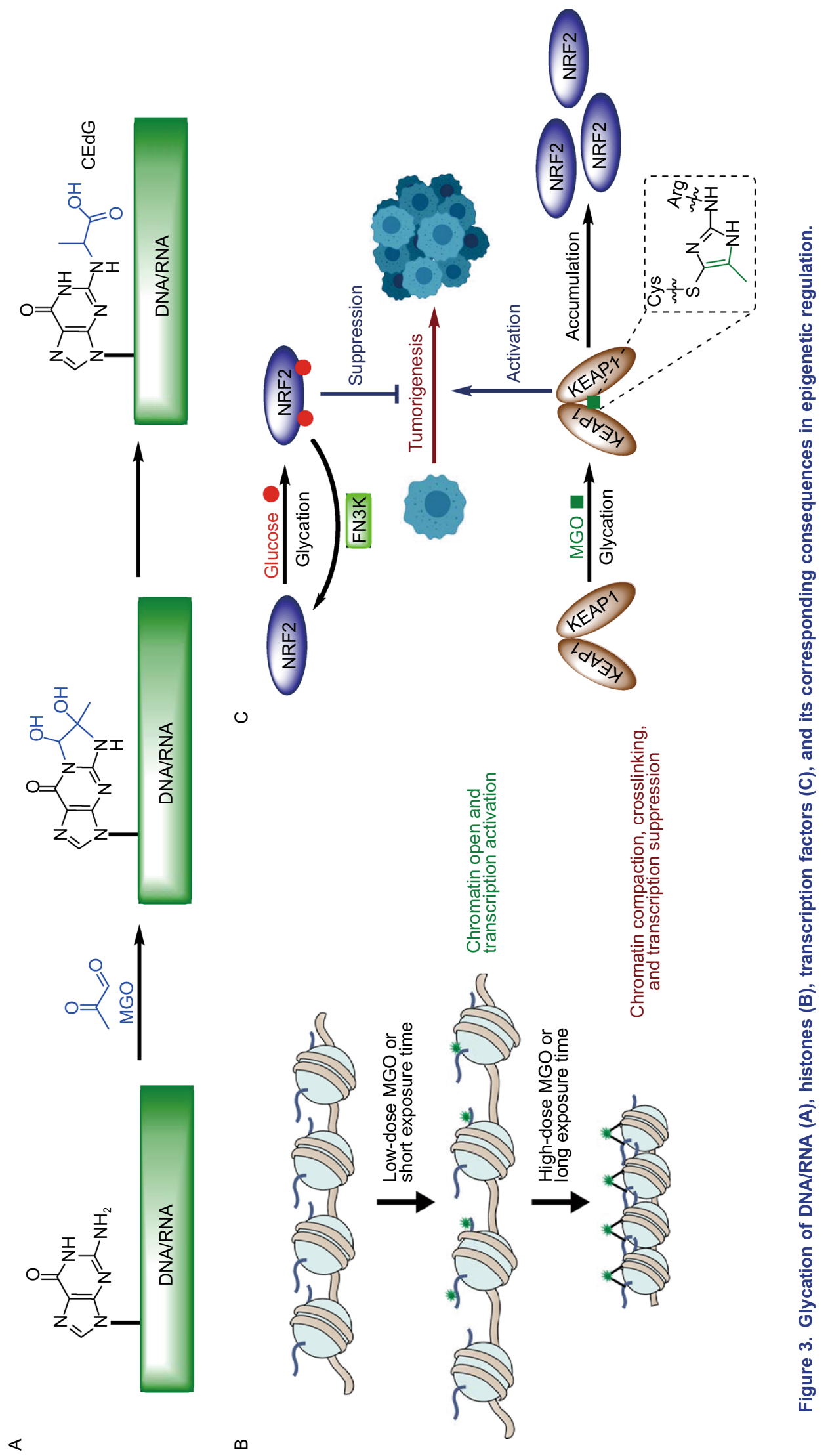




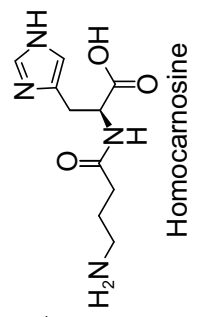

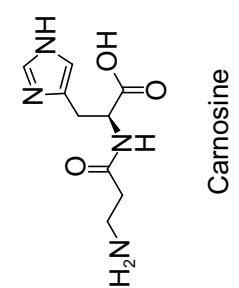<smiles>C[18O]C1CCCC1(C)C</smiles>

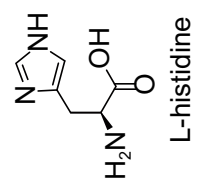

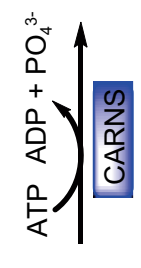

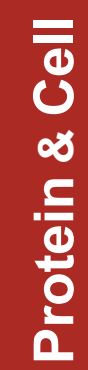

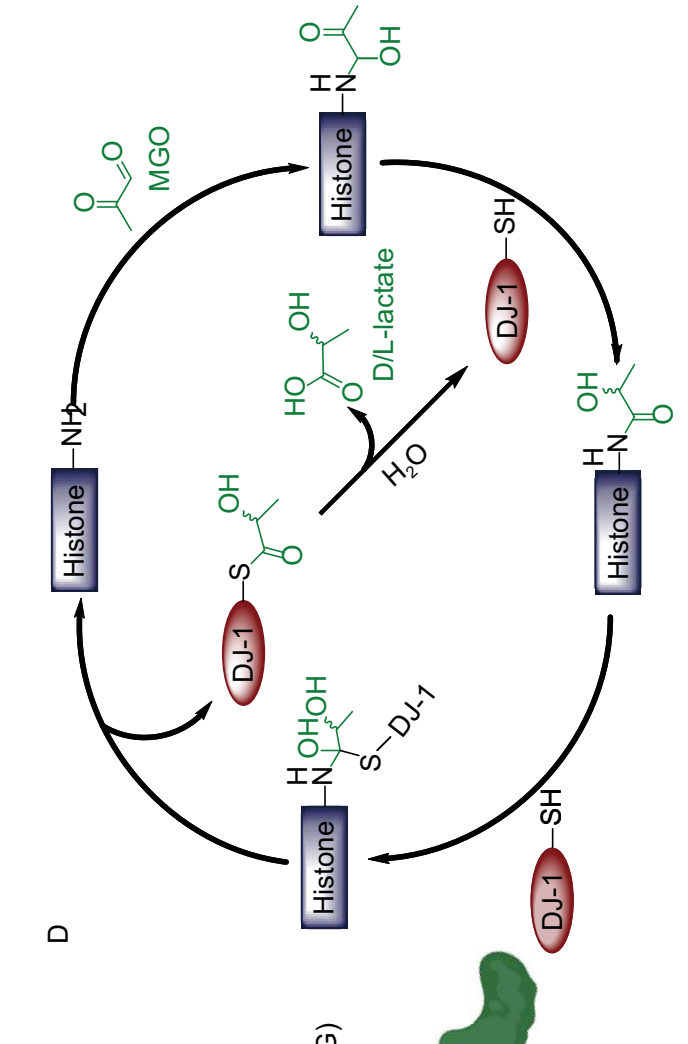

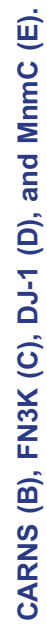
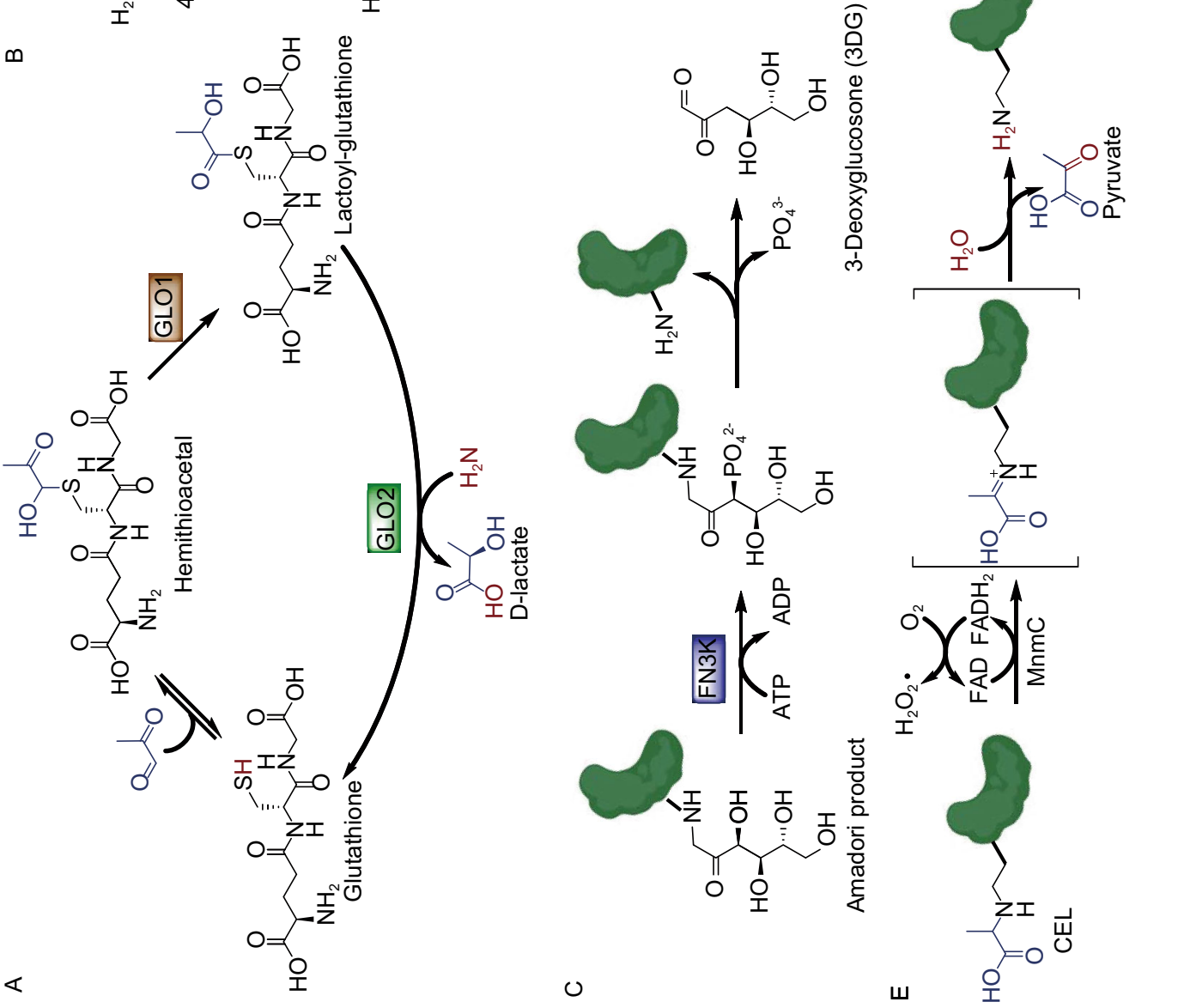

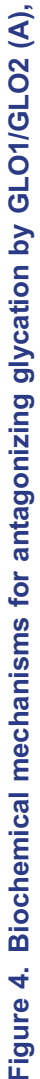


ameliorate cellular glycation damage (Zheng et al., 2019). These regulatory mechanisms include preventing the initial glycation by scavenging the free reducing sugar molecules as well as directly deglycating the modified substrates. In mammalian cells, scavenger systems systematically remove most of dicarbonyl molecules while deglycases such as FN3K (Szwergold et al., 2001), PAD4 (Zheng et al., 2019), and DJ-1 (Lee et al., 2012; Richarme et al., 2015; Richarme et al., 2017) are tasked with detecting and reversing the remainder.

In addition, Glyoxalases 1 (GLO1) and 2 (GLO2) together form a GLO1/GLO2 pathway that converts free MGO to D-lactate using glutathione (GSH) as a cofactor (Fig. 4A) (Xu and Chen, 2006; Distler and Palmer, 2012). First, the glutathione reacts with the dicarbonyl and forms a hemithioacetal which GLO1 can convert into lactoyl-glutathione (Distler and Palmer, 2012). GLO2 then hydrolyzes the lactoyl-glutathione, releasing $\mathrm{D}$-lactate and regenerating the glutathione (Xu and Chen, 2006). Carnosine synthase 1 (CARNS1) is an ATP-dependent enzyme that catalyzes the condensation of L-histidine and $\beta$-alanine to form the dipeptide metabolite carnosine (Fig. 4B) (Drozak et al., 2010). Carnosine is an endogenous small molecule scavenger for both reactive oxygen species (ROS) and reactive carbonyl species (RCS) (Cripps et al., 2017). These scavenging mechanisms inspired the development of drug leads, such as alagebrium chloride (ALT-711), for anti-glycation and anti-aging (Little et al., 2005).

As a kinase, FN3K catalyzes the C-3 phosphorylation of fructosamines formed by glucose-glycation, and the resulting unstable phosphate product undergoes spontaneous cleavage to yield 3-deoxyglucosone (3DG) and the regenerated amine (Fig. 4C) (Van Schaftingen et al., 2007). This enzymatic activity of FN3K has been demonstrated through both in vitro and in vivo experiments, however, its mitochondrial and cytosolic subcellular localization restricts FN3K from exhibiting its deglycation function as an eraser enzyme in the nucleus (Veiga da-Cunha et al., 2006). Alternatively, peptidyl arginine deiminase 4 (PAD4/PADI4) is known to be responsible for the conversion of arginine side-chains into citrulline (Suzuki et al., 2002) and antagonizing histone arginine methylation (Cuthbert et al., 2004; Wang et al., 2004). Recently, PAD4 has been shown to be capable of reversing MGO-glycation on $\mathrm{H} 3$ and $\mathrm{H} 4$ and converting their early glycated arginine adducts into citrulline (Zheng et al., 2019). DJ-1 (also referred to as PARK7) belongs to the peptidase C56 family of proteins and protects neurons against oxidative stress and cell death (Taira et al., 2004). Its catalytic cysteine residue $(\mathrm{C} 106)$ is positioned in a 'nucleophilic elbow' and responsible for both its oxidative stress sensing and deglycase activity (Nair et al., 2018). Previous studies indicate that DJ-1 erases early glyoxal (GO) and MGO-glycation adducts from both nucleotides and proteins (Fig. 4D) (Richarme and Dairou, 2017). Moreover, DJ-1 is also capable of converting free MGO into L/D-lactate through intermolecular hydrolysis of DJ-1 arginine and lysine residues that have reacted with the free MGO and formed early glycation intermediates (Toyoda et al., 2014; Zheng et al., 2019). Intriguingly, MnmC, which is involved in the bacterial tRNA-modification pathway and is FAD-dependent, was recently reported to be capable of reversing the AGEs, carboxyethyl-lysine (CEL) and carboxymethyl-lysine (CML), releasing an unmodified lysine structure (Kim et al., 2019). The engineered variant of $\mathrm{MnmC}$ has improved catalytic properties against CEL (Fig. 4E), thus providing insights into future protein-based therapies for AGE-induced protein damage (Kim et al., 2019).

\section{Glycation and human diseases}

Metabolic syndromes and diabetes increase the risks associated with neurodegenerative diseases, cancer, and hypoimmunity, among other disorders (Kopelman, 2007). Aldose-induced glycation opens a new door to expound this clinical phenomenon, however, an accurate mechanistic explanation for the correlation between glycation and human disease has remained elusive. Existing efforts indicate that glycation plays important pathophysiological roles in disease progression (Fournet et al., 2018). In cancer, imbalanced glycation could promote cancer by several mechniasms; the two recent transcription factor studies uncovered completely distinct biological implications of the NRF2/KEAP1 glycation pathway in cancer development. The glucose-induced glycation of NRF2 influences its protein-protein interaction properties and suppresses its oncogenic activity (Sanghvi et al., 2019), while the MGO-induced glycation of the tumor suppressor KEAP1 causes the accumulation of NRF2 in cells and thus promotes cancer progression (Fig. 3C) (Bollong et al., 2018). The two-stage model of histone MGOglycation (Fig. 3B) also provides a practical explanation for the observation that moderate amounts of MGO benefits cancer cell proliferation through the promotion of promiscuous transcription, while excess MGO causes chromatin crosslinking, subsequently abated transcription, and ultimately leads to cell death (Zheng et al., 2019).

In neurons, MGO-glycation of Nav1.8, a human sodium ion channel, intensifies nociceptive neuron firing and causes hyperalgesia in diabetic neuropathy (Bierhaus et al., 2012). Furthermore, for decades, AGEs have been correlated to neurodegenerative disorders such as Alzheimer's, Parkinson's, and Huntington's diseases (Li et al., 2012). Interestingly, the deglycase activity of DJ-1, which is also known as Parkinson disease protein 7 (PARK7), plays an important role in the progression of a familial form of Parkinson's disease (Repici and Giorgini, 2019). Given that core histones in neurons have extremely long half-lives due to lack in replication, one hypothesis proposes that DJ-1's deglycase activity is a protection mechanism against the development of neurodegenerative diseases (Ariga et al., 2013).

It has been well established that diabetic patients experience significant and characteristic hypoimmunity and/or immune dysfunction (Geerlings and Hoepelman, 1999). 
A

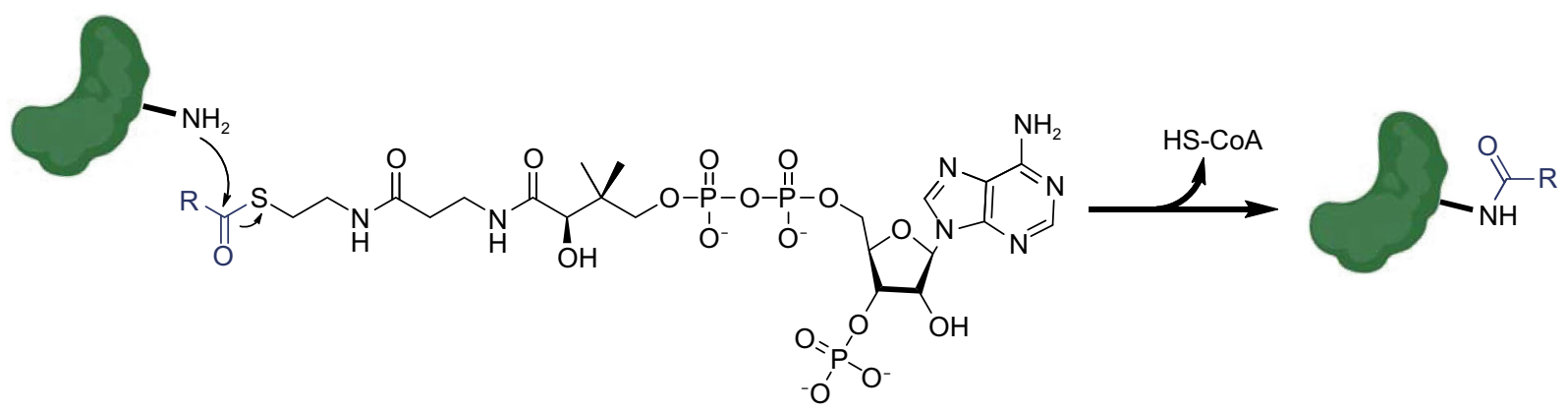

B

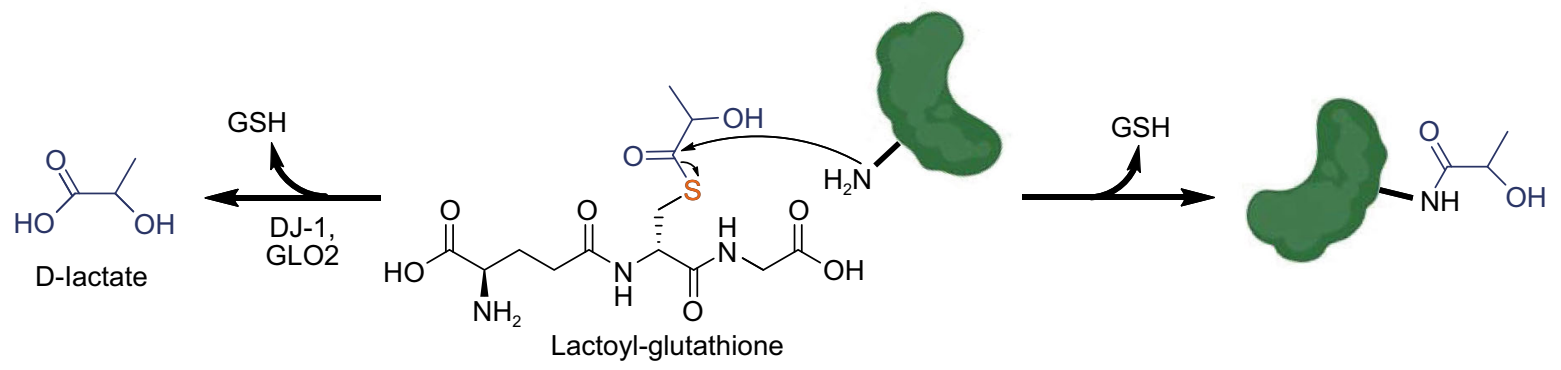

C

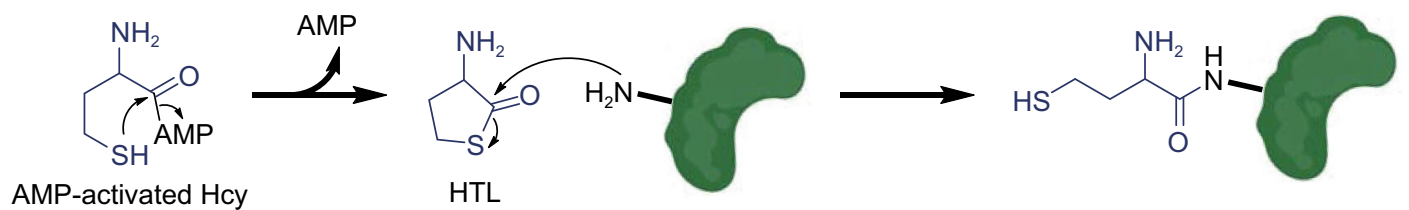

D

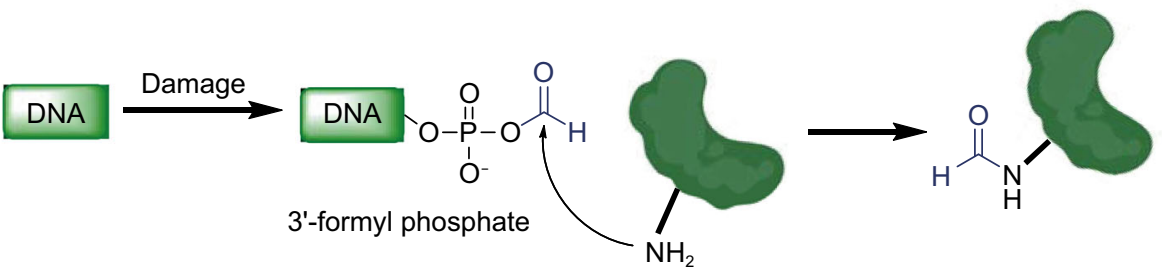

E

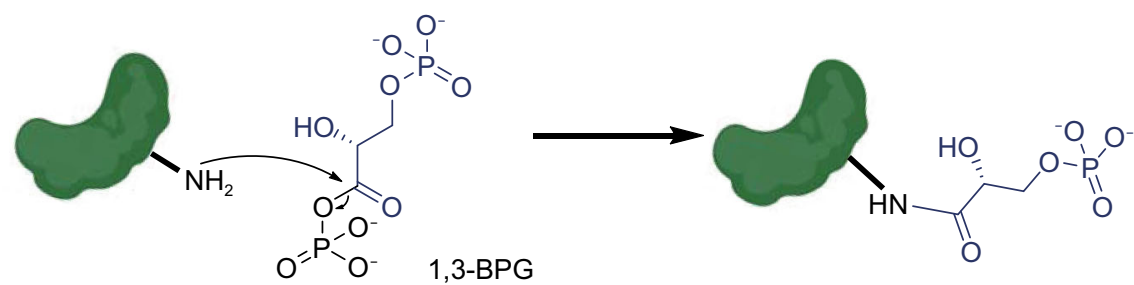

Figure 5. Non-enzymatic acylation induced by acyl-CoA (A), lactoyl-glutathione (B), HTL (C), 3'-formyl phosphate (D), and 1,3-BPG (E).

Previous studies also showed that high plasma concentrations of aldoses or reactive carbonyls, such as methylglyoxal, are associated with obesity and diabetes (Matafome et al., 2013). One possible mechanism for the formation of diabetic hypoimmunity is that aldose-mediated glycation of immunoglobulins and surface receptors causes immunocyte exhaustion, while histone and DNA glycation may lead to long term epigenetic impacts on immune responses (Wei et al., 2017; Teodorowicz et al., 2018).

\section{ACYLATION}

Acylation is a ubiquitous and important post-translational modification that regulates protein structure and function (Drazic et al., 2016). While most of the cellular protein 


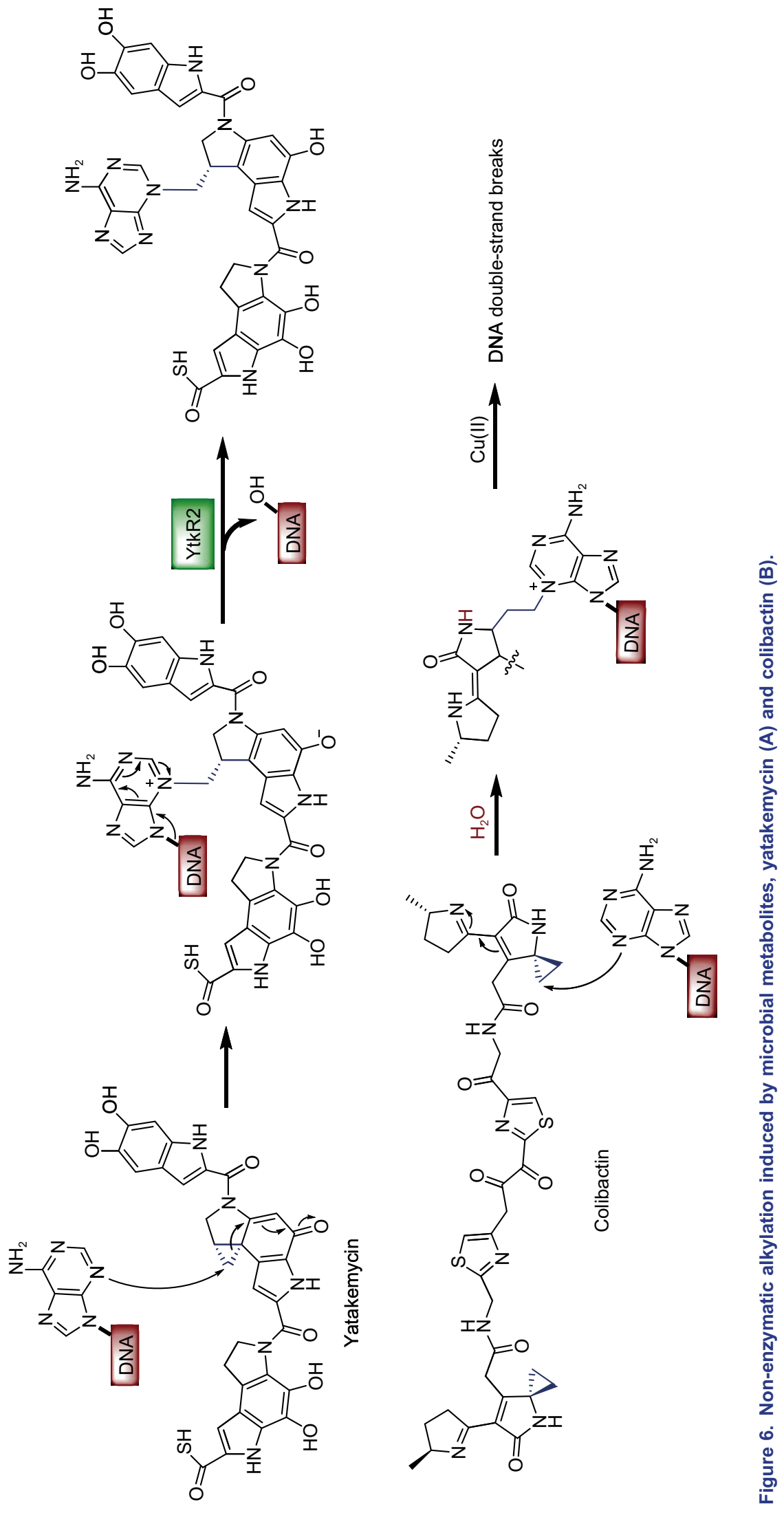

$\varangle$

$\infty$ 
A

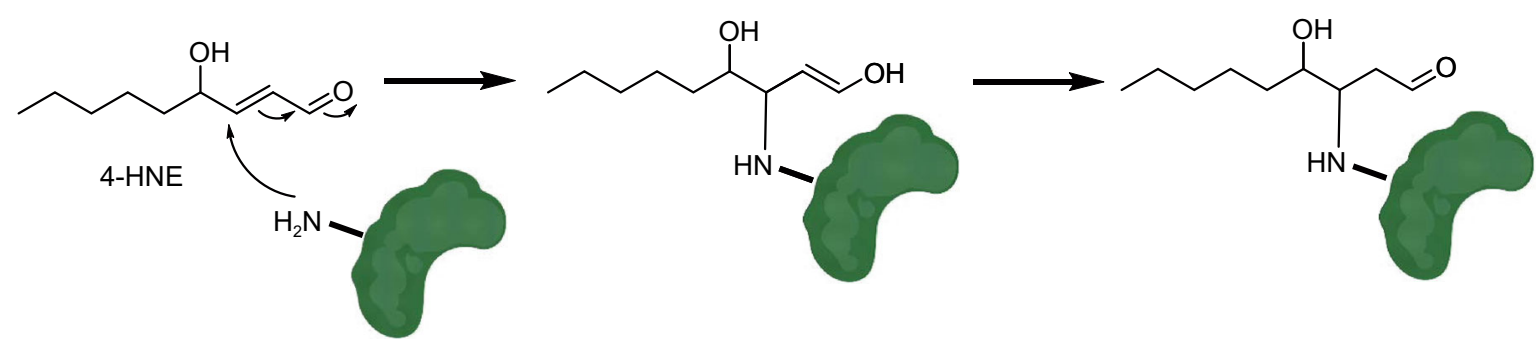

B

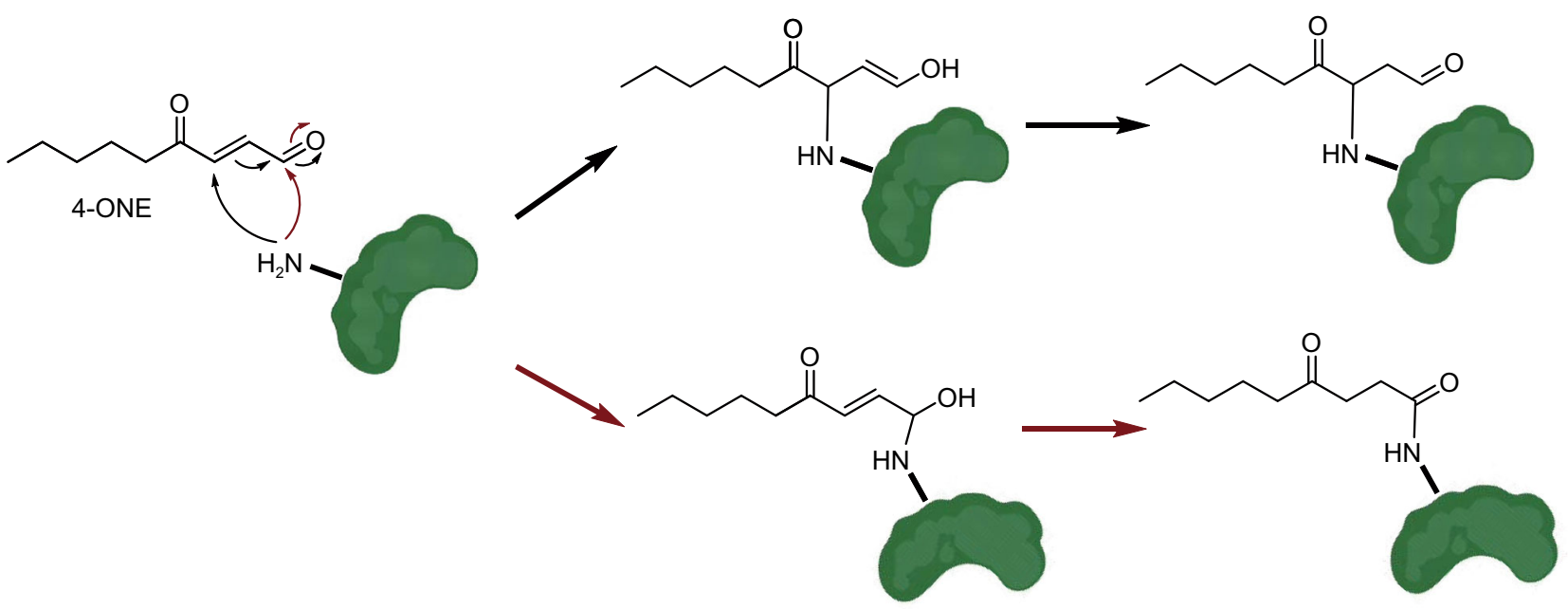

Figure 7. NECMs induced by 4-HNE (A) and 4-ONE (B) via the Michael addition.

acylations are facilitated by acyltransferases, non-enzymatic acylation induced by activated esters or anhydrides is also widely reported (Wagner and Hirschey, 2014). Importantly, some of these non-enzymatic acylation adducts were shown to be removed by common deacylases such as SIRT2 and SIRT3 (Wagner and Hirschey, 2014). Since most of the reported deacylases (such as the sirtuin family) are cofactor $\mathrm{NAD}^{+}$-dependent, the metabolic disorder of $\mathrm{NAD}^{+}$and $\mathrm{NADH}$ biosynthesis will also influence the deacetylation regulations in cells (Wagner and Hirschey, 2014; Drazic et al., 2016).

Coenzyme A-activated thioesters of different acids not only serve as donors for enzymatic acylation but also nonenzymatically modify proteins, generating acylated lysine residues (Fig. 5A). Recently, the $\mathrm{GSH}$-activated thioester of lactate has been reported to serve as the donor for lysine lactoylation of glycolytic enzymes (Fig. 5B) (Gaffney et al., 2019) while CoA-activated lactate serves a similar function on histones (Zhang et al., 2019). The lactoylation donor, lactoyl-glutathione, can be specifically hydrolyzed by GLO2 and DJ-1 (Fig. 5B) (Xu and Chen, 2006; Matsuda et al., 2017). Interestingly, since GSH-activated lactate is biosynthesized by GLO1 from MGO (Fig. 4A) (Distler and Palmer, 2012), lactoylation is a new type of NECM indirectly induced by MGO. Homocysteine thiolactone (HTL) is an intramolecular thioester of homocysteine (Hcy), which induces nonenzymatic homocysteinylation on lysine residues (Fig. 5C) (Jakubowski, 2000). Recent studies in neuronal tissues have shown that multiple residues of all four core histones can be modified by HTL, subsequently down-regulating the expression of selected neuronal-tube closure-related genes (Xu et al., 2015; Zhang et al., 2018). This discovery provides a potential mechanistic explanation for the correlation between high maternal Hcy levels and developmental neuronal tube defects.

Anhydrides are more active than esters, making them even better donors for non-enzymatic acylation. An anhydride generated during DNA damage, 3'-formyl phosphate, serves as an acyl donor for lysine formylation (Fig. 5D) (Jiang et al., 2007). An additional anhydride, 1,3-bisphosphoglycerate (1,3-BPG), is a primary glycolytic intermediate that selectively reacts with lysine residues forming 3-phosphoglyceryl-lysine (pgK, Fig. 5E) (Moellering and Cravatt, 2013). Interestingly, pgK modifications have been demonstrated to inhibit glycolytic enzymes and accumulate on proteins generating a potential feedback mechanism for glycolysis regulation (Moellering and Cravatt, 2013). 
A

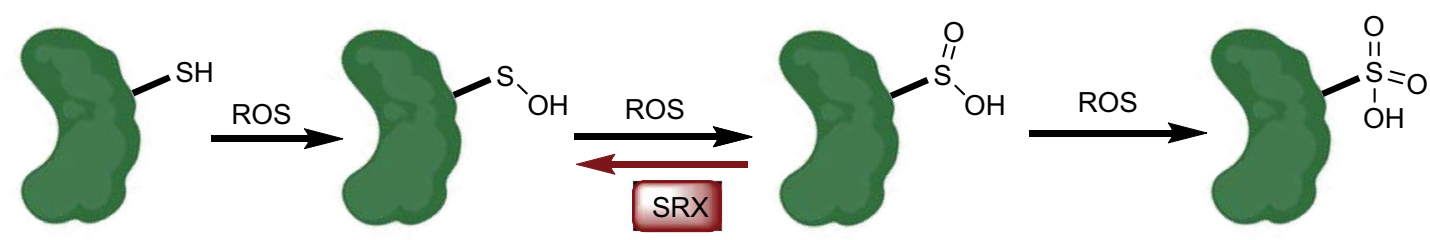

B<smiles>N[C@@H](CCC(=O)N[C@@H](CS)C(=O)NCC(=O)O)C(=O)O</smiles><smiles>C[N+](C)(C)[C@H](Cc1cnc(S)[nH]1)C(=O)O</smiles>

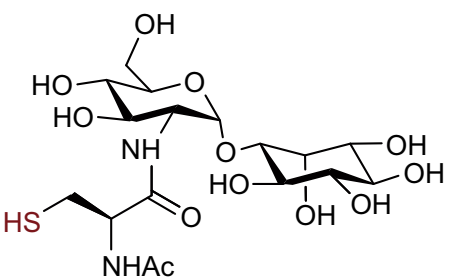

GSH

EGT

$\mathrm{HSH}$

C

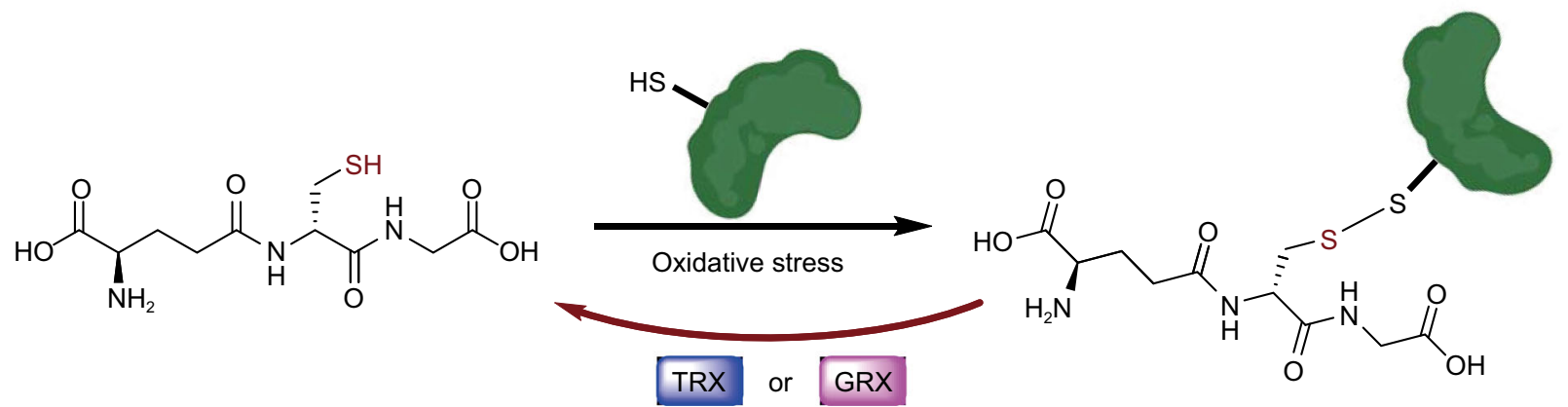

Figure 8. Non-enzymatic redox reactions. (A) Different oxidation states of cysteine side-chain. (B) Representative thiol-containing redox metabolites. (C) Glutathione oxidation of protein cysteine side-chain.

\section{ALKYLATION}

Alkylation of proteins or nucleosides is usually induced by alkylating agents ingested from the environment, such as methylnitrosourea (MNU) and tobacco-specific nitrosamines (Shuker et al., 1993). However, the non-enzymatic alkylations induced by endogenous metabolites (e.g., S-adenosylL-methionine) have been reported to be potentially mutagenic reactions (Rydberg and Lindahl, 1982). Compounds with ring strain, such as the microbial metabolite, yatakemycin, which contains a unique chiral cyclopropane moiety, also exhibit alkylating activities (Parrish et al., 2003). Yatakemycin is a DNA-alkylating agent with remarkable cytotoxicity against cancer cells, and its resulting alkylation adducts can be removed by the DNA glycosylase, YtkR2 (Fig. 6A) (Xu et al., 2012). Another alkylating agent, colibactin (Fig. 6B), is a genotoxic secondary metabolite produced by microorganisms harboring the pks genomic island, including certain gut commensal Escherichia coli strains $\left(p k s^{+}\right.$E. coli). Alkylation by colibactin causes multiple epigenetic impacts on the host organisms, including cell cycle arrest, DNA double-strand breaks, and senescence (Wilson et al., 2019). Moreover, colibactin-producing $E$. coli have been shown to accelerate colorectal cancer tumor progression, a finding that defined a new link between gut microbiota and human disease (Dalmasso et al., 2014).

\section{MICHAEL ADDITION}

Enones, also termed $\alpha, \beta$-unsaturated carbonyls, are reactive electrophilic agents that can non-enzymatically modify nucleophilic groups of proteins and nucleosides (e.g., - $\mathrm{SH}$, $\mathrm{NH}_{2}$ and $-\mathrm{OH}$ ) via the Michael addition. The oxidation of cellular lipids generate $\alpha, \beta$-unsaturated alkenals, including 4-hydroxy-2-nonenal (4-HNE) and 4-oxo-2-nonenal (4-ONE) (Doorn and Petersen, 2002; Näsström et al., 2011). These electrophilic metabolites form adducts on both DNA and histone proteins, altering the structures and functions of chromatin (Fig. 7) (Sun et al., 2017). The 4-ONE non-enzymatic addition to histones $\mathrm{H} 3$ and $\mathrm{H} 4$ was reported to prevent nucleosome assembly and occupy histone PTM sites that are essential for epigenetic regulations (e.g., H3K23 and H3K27) (Galligan et al., 2014). Similar to some acylations, 
the 4-ONE histone NECMs can be hydrolyzed by the deacylase, SIRT2 (Cui et al., 2017). These results suggest a connection between metabolic disorders, oxidative stress, and epigenetic regulation.

\section{REDOX REACTION}

Redox reactions are some of the most important and ubiquitous chemical processes in all organisms (Ochs, 2019). Reactive oxygen species (ROS), such as $\mathrm{H}_{2} \mathrm{O}_{2}$, are continuously produced and scavenged in cells, and can oxidize cysteine thiols into sulfenic, sulfinic, or sulfonic acid (Fig. 8A) (Chauvin and Pratt, 2017). These oxidations may often induce alterations in the structure and functions of proteins, which often act as sensors to induce a downstream cellular response to the oxidative state changes (Marinho et al., 2014). Although the precise pathological roles of ROS remain controversial (Schumacker, 2006), in human cells there are multiple oxidative stress sensor proteins including GAPDH and DJ-1, which have key regulatory cysteines sensitive to ROS fluctuations (Duan et al., 2008). Cells have evolved multiple mechanisms to complete the redox cycles, such as sulfiredoxin (SRX), a reported sulfinic acid reductase that can reduce cysteine sulfinylation (Fig. 8A) (Basu and Koonin, 2005). Moreover, cells produce metabolites possessing thiol groups to reduce ROS and protect cellular components from oxidative damage (Poole, 2015). This class of reducing agents includes among others, GSH, ergothioneine (EGT) and mycothiol $(\mathrm{MSH})$, which all play critical roles in the distinct domains of life (Fig. 8B) (Hand and Honek, 2005; Van Laer et al., 2013). Intriguingly, some of these small-molecule thiols are reported to non-enzymatically modify protein cysteine residues via reduction, and this modification can be enzymatically reversed by deglutathionylase enzymes such as glutaredoxin (GRX) and thioredoxin (TRX) (Fig. 8C) (Greetham et al., 2010). For example, H3 cysteines were shown to be modified by GSH through S-glutathionylation, which leads to a looser chromatin structure (García-Giménez et al., 2013). Importantly, the levels of S-glutathionylation increase during cellular proliferation and decrease during aging, highlighting a potential physiological causal relationship between non-enzymatic redox reactions and human health (Hake and Allis, 2006).

\section{CONCLUSIONS AND PERSPECTIVES}

While NECMs are long-established in biochemistry, emergent questions surrounding aberrant metabolism-related human diseases have revitalized renewed interest in them. Although membrane proteins are the primary targets of serum metabolites (Matsuda et al., 2013), core histones are the principal targets of intracellular metabolites during NECM formation (Zheng et al., 2019). Because of their long halflives and nucleophilic N-terminal tails, histones accumulate stable enzymatic and non-enzymatic PTMs. DNA and histone NECMs, spontaneously induced by multiple classes of reactive metabolites including ROS and RCS, providing a direct causal link between metabolism and long-term epigenetic dysregulation. We propose that histones adopt the roles of 'NECM sponges' in cells as part of an epigenetic feedback loop in metabolic disorders.

Incidentally, some of the NECM-inducing reactive metabolites are exogenous to human cells. Metabolites produced by human gastrointestinal microbiota are known to exhibit essential functions in quorum sensing and virulence (Li et al., 2018). However, a substantial body of evidence has shown that the reactive microbial metabolites, such as colibactin (Dalmasso et al., 2014) and peptide aldehydes (Guo et al., 2017), directly modify host DNA or proteins to influence the cell cycle and immune response. The studies of reactive metabolite-induced NECMs will continue to aid in understanding pathophysiological host-microbe interactions such as the gut-brain axis (Cryan et al., 2019).

Relative to canonical and enzymatically regulated biomolecule modifications, NECMs are less characterized due to the structural diversity, dynamic nature, and instability of the adducts formed (Zhu et al., 2018). There is a critical need for novel approaches to study NECMs including the development of high-resolution trace mass spectrometry, chemical probes for specific enrichment, and site-specific antibodies. Individual and customized NECMs can also be specifically introduced into designated targets in vivo using intein-mediated protein splicing (Maksimovic et al., 2019) and amber codon suppression (Zhang et al., 2003).

Overall, non-enzymatic covalent modifications, which are identified as a ubiquitous biomarker on biomacromolecules, have extended the so-called 'histone code' (Jenuwein and Allis, 2001) and become a new link between metabolic disorders and epigenetic dysregulation. However, because epigenetic changes are heritable (Trerotola et al., 2015), cellular microenvironment-driven DNA and histone NECMs have potential implications in far-reaching processes such as embryonic development, ultimately resulting in postnatal impacts on organisms (Jawahar et al., 2015). Even though the interplay between metabolism and epigenetics has been well established in the past few years (Etchegaray and Mostoslavsky, 2016; Reid et al., 2017; Tzika et al., 2018; Montellier and Gaucher, 2019), recent studies of metaboliteinduced epigenetic modifications opened a new door for understanding the missing links between them. Moreover, NECMs that target non-epigenetic proteins may also induce long-term biological effects and require further studies.

\section{ACKNOWLEDGEMENTS}

Work in the David lab is supported by R21 DA044767, CCSG core grant P30 CA008748, and SPORE P50-CA192937 from the National Institutes of Health. In addition, work in the lab is supported by the Tri-institutional Therapeutic Discovery Institute, the Mr. William $\mathrm{H}$. Goodwin and Mrs. Alice Goodwin and the Commonwealth Foundation for Cancer Research and the Center for Experimental 
Therapeutics at MSKCC, the Pershing Square Sohn Cancer Research Alliance, and Cycle for Survival. Y.D. is a Josie Robertson Young Investigator. Additionally, YD is supported by the Parker Institute for Cancer Immunotherapy and the Anna Fuller Cancer Research Foundation.

\section{ABBREVIATIONS}

AGE, advanced glycation end product; Arg, arginine; 1,3-BPG, 1,3bisphosphoglycerate; CARNS1, carnosine synthase 1; CEdG, $\mathrm{N}^{2}$ carboxyethyl-2'-deoxyguanosine; CEL, carboxyethyl-lysine; CML, carboxymethyl-lysine; Co-A, coenzyme A; CUL3, cullin 3; CYP2E1, cytochrome P450 family 2 subfamily $E$ member 1; 3DG, 3-deoxyglucosone; DHAP, dihydroxyacetone phosphate; DNA, deoxyribonucleic acid; E. coli, Escherichia coli; EGT, ergothioneine; FN3K, fructosamine 3 kinas; GA3P, glyceraldehyde-3-phosphate; GAPDH, glyceraldehyde 3-phosphate dehydrogenase; GIcNAc, N-acetylglucosamine; GLO, glyoxalases; GO, glyoxal; GRX, glutaredoxin; GSH, glutathione; Hcy, homocysteine; 4-HNE, 4-hydroxy-2-nonenal; HTL, homocysteine thiolactone; KEAP1, Kelch ECH associating protein 1; Lys, lysine; MGO, methylglyoxal; MNU, methylnitrosourea; $\mathrm{MSH}$, mycothiol; NAD, nicotinamide adenine dinucleotide; NECM, nonenzymatic covalent modification; NRF2, nuclear factor erythroid 2-related factor; OGT, O-GICNAc transferase; 4-ONE, 4-oxo-2nonenal; PAD4, protein arginine deiminase 4; PARK7, Parkinson disease protein 7; pgK, 3-phosphoglyceryl-lysine; PTM, post-translational modification; RCS, reactive carbonyl species; RNA, ribonucleic acid; ROS, reactive oxygen species; SAM, S-adenosyl methionine; SIRT, sirtuin; SRX, sulfiredoxin; SSAO, semicarbazide-sensitive amine oxidase; TF, transcription factor; TRX, thioredoxin; UDP, uridine diphosphate

\section{COMPLIANCE WITH ETHICS GUIDELINES}

All the authors of this paper declare that they have no conflict of interest. This article does not contain any studies with human or animal subjects performed by the any of the authors.

\section{OPEN ACCESS}

This article is licensed under a Creative Commons Attribution 4.0 International License, which permits use, sharing, adaptation, distribution and reproduction in any medium or format, as long as you give appropriate credit to the original author(s) and the source, provide a link to the Creative Commons licence, and indicate if changes were made. The images or other third party material in this article are included in the article's Creative Commons licence, unless indicated otherwise in a credit line to the material. If material is not included in the article's Creative Commons licence and your intended use is not permitted by statutory regulation or exceeds the permitted use, you will need to obtain permission directly from the copyright holder. To view a copy of this licence, visit http:// creativecommons.org/licenses/by/4.0/.

\section{REFERENCES}

Allaman I, Bélanger M, Magistretti PJ (2015) Methylglyoxal, the dark side of glycolysis. Front Neurosci 9:23

Ammar R, Torti D, Tsui K, Gebbia M, Durbic T, Bader GD, Giaever G, Nislow C (2012) Chromatin is an ancient innovation conserved between Archaea and Eukarya. Elife 1:e00078

Ariga H, Takahashi-Niki K, Kato I, Maita H, Niki T, Iguchi-Ariga SM (2013) Neuroprotective function of DJ-1 in Parkinson's disease. Oxid Med Cell Longev 2013:683920

Bannister AJ, Kouzarides T (2011) Regulation of chromatin by histone modifications. Cell Res 21:381-395

Basu MK, Koonin EV (2005) Evolution of eukaryotic cysteine sulfinic acid reductase, sulfiredoxin (Srx), from bacterial chromosome partitioning protein ParB. Cell Cycle 4:947-952

Bierhaus A, Fleming T, Stoyanov S, Leffler A, Babes A, Neacsu C, Sauer SK, Eberhardt M, Schnölzer M, Lasitschka F et al (2012) Methylglyoxal modification of Nav1.8 facilitates nociceptive neuron firing and causes hyperalgesia in diabetic neuropathy. Nat Med 18:926-933

Bollong MJ, Lee G, Coukos JS, Yun H, Zambaldo C, Chang JW, Chin EN, Ahmad I, Chatterjee AK, Lairson LL et al (2018) A metabolite-derived protein modification integrates glycolysis with KEAP1-NRF2 signalling. Nature 562:600-604

Bondoc FY, Bao Z, Hu WY, Gonzalez FJ, Wang Y, Yang CS, Hong JY (1999) Acetone catabolism by cytochrome P450 2E1: studies with CYP2E1-null mice. Biochem Pharmacol 58:461-463

Chauvin JR, Pratt DA (2017) On the reactions of thiols, sulfenic acids, and sulfinic acids with hydrogen peroxide. Angew Chem Int Ed Engl 56:6255-6259

Chen Y, Qin W, Li Z, Guo Z, Liu Y, Lan T, Wang C (2019) Sitespecific chemoproteomic profiling of targets of glyoxal. Future Med Chem 11:2979-2987

Commerford SL, Carsten AL, Cronkite EP (1982) Histone turnover within nonproliferating cells. Proc Natl Acad Sci USA 79:1163-1165

Cripps MJ, Hanna K, Lavilla C Jr, Sayers SR, Caton PW, Sims C, De Girolamo L, Sale C, Turner MD (2017) Carnosine scavenging of glucolipotoxic free radicals enhances insulin secretion and glucose uptake. Sci Rep 7:13313

Cryan JF, O'Riordan KJ, Cowan CSM, Sandhu KV, Bastiaanssen TFS, Boehme M, Codagnone MG, Cussotto S, Fulling C, Golubeva AV et al (2019) The microbiota-gut-brain axis. Physiol Rev 99:1877-2013

Cui Y, Li X, Lin J, Hao Q, Li XD (2017) Histone ketoamide adduction by 4-oxo-2-nonenal is a reversible posttranslational modification regulated by Sirt2. ACS Chem Biol 12:47-51

Cuthbert GL, Daujat S, Snowden AW, Erdjument-Bromage H, Hagiwara T, Yamada M, Schneider R, Gregory PD, Tempst P, Bannister AJ et al (2004) Histone deimination antagonizes arginine methylation. Cell 118:545-553

Dalmasso G, Cougnoux A, Delmas J, Darfeuille-Michaud A, Bonnet $\mathrm{R}$ (2014) The bacterial genotoxin colibactin promotes colon tumor growth by modifying the tumor microenvironment. Gut Microbes $5: 675-680$ 
Distler MG, Palmer AA (2012) Role of Glyoxalase 1 (Glo1) and methylglyoxal (MG) in behavior: recent advances and mechanistic insights. Front Genet 3:250

Doorn JA, Petersen DR (2002) Covalent modification of amino acid nucleophiles by the lipid peroxidation products 4-hydroxy-2nonenal and 4-oxo-2-nonenal. Chem Res Toxicol 15:1445-1450

Drazic A, Myklebust LM, Ree R, Arnesen T (2016) The world of protein acetylation. Biochim Biophys Acta 1864:1372-1401

Drozak J, Veiga-da-Cunha M, Vertommen D, Stroobant V, Van Schaftingen E (2010) Molecular identification of carnosine synthase as ATP-grasp domain-containing protein 1 (ATPGD1). J Biol Chem 285:9346-9356

Duan X, Kelsen SG, Merali S (2008) Proteomic analysis of oxidative stress-responsive proteins in human pneumocytes: insight into the regulation of DJ-1 expression. J Proteome Res 7:4955-4961

Erler J, Zhang R, Petridis L, Cheng X, Smith JC, Langowski J (2014) The role of histone tails in the nucleosome: a computational study. Biophys J 107:2911-2922

Etchegaray JP, Mostoslavsky R (2016) Interplay between metabolism and epigenetics: A nuclear adaptation to environmental changes. Mol Cell 62:695-711

Fournet M, Bonté F, Desmoulière A (2018) Glycation damage: A possible hub for major pathophysiological disorders and aging. Aging Dis 9:880-900

Gaffney DO, Jennings EQ, Anderson CC, Marentette JO, Shi T, Schou Oxvig AM, Streeter MD, Johannsen M, Spiegel DA, Chapman E et al (2019) Non-enzymatic lysine lactoylation of glycolytic enzymes. Cell Chem Bio. https://doi.org/10.1016/j. chembiol.2019.11.005

Galligan JJ, Rose KL, Beavers WN, Hill S, Tallman KA, Tansey WP, Marnett LJ (2014) Stable histone adduction by 4-oxo-2-nonenal: a potential link between oxidative stress and epigenetics. J Am Chem Soc 136:11864-11866

Galligan JJ, Wepy JA, Streeter MD, Kingsley PJ, Mitchener MM, Wauchope OR, Beavers WN, Rose KL, Wang T, Spiegel DA et al (2018) Methylglyoxal-derived posttranslational arginine modifications are abundant histone marks. Proc Natl Acad Sci U S A 115:9228-9233

García-Giménez JL, Òlaso G, Hake SB, Bönisch C, Wiedemann SM, Markovic J, Dasí F, Gimeno A, Pérez-Quilis C, Palacios O et al (2013) Histone H3 glutathionylation in proliferating mammalian cells destabilizes nucleosomal structure. Antioxid Redox Signal 19:1305-1320

Geerlings SE, Hoepelman AI (1999) Immune dysfunction in patients with diabetes mellitus (DM). FEMS Immunol Med Microbiol 26:259-265

Greetham D, Vickerstaff J, Shenton D, Perrone GG, Dawes IW, Grant CM (2010) Thioredoxins function as deglutathionylase enzymes in the yeast Saccharomyces cerevisiae. BMC Biochem 11:3

Guo CJ, Chang FY, Wyche TP, Backus KM, Acker TM, Funabashi M, Taketani M, Donia MS, Nayfach S, Pollard KS et al (2017) Discovery of reactive microbiota-derived metabolites that inhibit host proteases. Cell 168:517-526

Hake SB, Allis CD (2006) Histone $\mathrm{H} 3$ variants and their potential role in indexing mammalian genomes: the "H3 barcode hypothesis". Proc Natl Acad Sci USA 103:6428-6435
Hand CE, Honek JF (2005) Biological chemistry of naturally occurring thiols of microbial and marine origin. $\mathrm{J}$ Nat Prod 68:293-308

Harmel R, Fiedler D (2018) Features and regulation of nonenzymatic post-translational modifications. Nat Chem Biol 14:244-252

Hellwig M, Henle T (2014) Baking, ageing, diabetes: a short history of the Maillard reaction. Angew Chem Int Ed Engl 53(39):1031610329

Jakubowski H (2000) Homocysteine thiolactone: metabolic origin and protein homocysteinylation in humans. J Nutr 130:377S$381 \mathrm{~S}$

Janke R, Dodson AE, Rine J (2015) Metabolism and epigenetics. Annu Rev Cell Dev Biol 31:473-496

Jaramillo R, Shuck SC, Chan YS, Liu X, Bates SE, Lim PP, Tamae D, Lacoste S, O'Connor TR, Termini J (2017) DNA Advanced glycation end products (DNA-AGEs) are elevated in urine and tissue in an animal model of type 2 diabetes. Chem Res Toxicol 30:689-698

Jawahar MC, Murgatroyd C, Harrison EL, Baune BT (2015) Epigenetic alterations following early postnatal stress: a review on novel aetiological mechanisms of common psychiatric disorders. Clin Epigenet 7:122

Jenuwein T, Allis CD (2001) Translating the histone code. Science 293:1074-1080

Jiang T, Zhou X, Taghizadeh K, Dong M, Dedon PC (2007) $\mathrm{N}$-formylation of lysine in histone proteins as a secondary modification arising from oxidative DNA damage. Proc Natl Acad Sci USA 104:60-65

Kansanen E, Kuosmanen SM, Leinonen H, Levonen AL (2013) The Keap1-Nrf2 pathway: Mechanisms of activation and dysregulation in cancer. Redox Biol 1:45-49

Kawai Y, Garduño L, Theodore M, Yang J, Arinze IJ (2011) Acetylation-deacetylation of the transcription factor Nrf2 (nuclear factor erythroid 2-related factor 2) regulates its transcriptional activity and nucleocytoplasmic localization. J Biol Chem 286:7629-7640

Keum YS (2011) Regulation of the Keap1/Nrf2 system by chemopreventive sulforaphane: implications of posttranslational modifications. Ann N Y Acad Sci 1229:184-189

Kim NY, Goddard TN, Sohn S, Spiegel DA, Crawford JM (2019) Biocatalytic reversal of advanced glycation end product modification. Chembiochem 20:2402-2410

Kopelman P (2007) Health risks associated with overweight and obesity. Obes Rev 1:13-17

Lee JY, Song J, Kwon K, Jang S, Kim C, Baek K, Kim J, Park C (2012) Human DJ-1 and its homologs are novel glyoxalases. Hum Mol Genet 21:3215-3225

Li J, Liu D, Sun L, Lu Y, Zhang Z (2012) Advanced glycation end products and neurodegenerative diseases: mechanisms and perspective. J Neurol Sci 317:1-5

Li Z, Quan G, Jiang X, Yang Y, Ding X, Zhang D, Wang X, Hardwidge PR, Ren W, Zhu G (2018) Effects of metabolites derived from gut microbiota and hosts on pathogens. Front Cell Infect Microbiol 8:314 
Linetsky M, Shipova E, Cheng R, Ortwerth BJ (2007) Glycation by ascorbic acid oxidation products leads to the aggregation of lens proteins. Biochim Biophys Acta 1782:22-34

Little WC, Zile MR, Kitzman DW, Hundley WG, O'Brien TX, Degroof RC (2005) The effect of alagebrium chloride (ALT-711), a novel glucose cross-link breaker, in the treatment of elderly patients with diastolic heart failure. J Card Fail 11:191-195

Maksimovic I, Ray D, Zheng Q, David Y (2019) Utilizing intein transsplicing for in vivo generation of site-specifically modified proteins. Methods Enzymol 626:203-222

Marinho HS, Real C, Cyrne L, Soares H, Antunes F (2014) Hydrogen peroxide sensing, signaling and regulation of transcription factors. Redox Biol 2:535-562

Matafome P, Sena C, Seiça R (2013) Methylglyoxal, obesity, and diabetes. Endocrine 43:472-484

Matsuda R, Bi C, Anguizola J, Sobansky M, Rodriguez E, Vargas Badilla J, Zheng X, Hage B, Hage DS (2013) Studies of metabolite-protein interactions: a review. J Chromatogr B Analyt Technol Biomed Life Sci 966:48-58

Matsuda N, Kimura M, Queliconi BB, Kojima W, Mishima M, Takagi K, Koyano F, Yamano K, Mizushima T, Ito $Y$ et al (2017) Parkinson's disease-related DJ-1 functions in thiol quality control against aldehyde attack in vitro. Sci Rep 7:12816

May-Zhang LS, Yermalitsky V, Huang J, Pleasent T, Borja MS, Oda MN, Jerome WG, Yancey PG, Linton MF, Davies SS (2018) Modification by isolevuglandins, highly reactive $\mathrm{Y}$-ketoaldehydes, deleteriously alters high-density lipoprotein structure and function. J Biol Chem 293:9176-9187

McGinty RK, Tan S (2015) Nucleosome structure and function. Chem Rev 115:2255-2273

Mitchell D 3rd, Ritchey LE, Park H, Babitzke P, Assmann SM, Bevilacqua PC (2018) Glyoxals as in vivo RNA structural probes of guanine base-pairing. RNA 24:114-124

Moellering RE, Cravatt BF (2013) Functional lysine modification by an intrinsically reactive primary glycolytic metabolite. Science 341:549-553

Montellier E, Gaucher J (2019) Targeting the interplay between metabolism and epigenetics in cancer. Curr Opin Oncol 31:92-99

Nair DN, Prasad R, Singhal N, Bhattacharjee M, Sudhakar R, Singh P, Thanumalayan S, Kiran U, Sharma Y, Sijwali PS (2018) A conserved human DJ1-subfamily motif (DJSM) is critical for antioxidative and deglycase activities of Plasmodium falciparum DJ1. Mol Biochem Parasitol 222:70-80

Näsström T, Fagerqvist $T$, Barbu $M$, Karlsson $M$, Nikolajeff $F$, Kasrayan A, Ekberg M, Lannfelt L, Ingelsson M, Bergström J (2011) The lipid peroxidation products 4-oxo-2-nonenal and 4-hydroxy-2-nonenal promote the formation of $\alpha$-synuclein oligomers with distinct biochemical, morphological, and functional properties. Free Radic Biol Med 50:428-437

Obata T (2006) Diabetes and semicarbazide-sensitive amine oxidase (SSAO) activity: a review. Life Sci 79:417-422

Ochs R (2019) An idea to explore: understanding redox reactions in biochemistry. Biochem Mol Biol Educ 47:25-28

Parrish JP, Kastrinsky DB, Wolkenberg SE, Igarashi Y, Boger DL (2003) NA alkylation properties of yatakemycin. J Am Chem Soc 125:10971-10976
Poole LB (2015) The basics of thiols and cysteines in redox biology and chemistry. Free Radic Biol Med 80:148-157

Raiber EA, Portella G, Martínez Cuesta S, Hardisty R, Murat P, Li Z, lurlaro M, Dean W, Spindel J, Beraldi D et al (2018) 5-Formylcytosine organizes nucleosomes and forms Schiff base interactions with histones in mouse embryonic stem cells. Nat Chem 10:1258-1266

Reid MA, Dai Z, Locasale JW (2017) The impact of cellular metabolism on chromatin dynamics and epigenetics. Nat Cell Biol 19:1298-1306

Repici M, Giorgini F (2019) DJ-1 in Parkinson's disease: Clinical insights and therapeutic perspectives. J Clin Med 8:1377

Richarme G, Dairou J (2017) Parkinsonism-associated protein DJ-1 is a bona fide deglycase. Biochem Biophys Res Commun 483:387-391

Richarme G, Mihoub M, Dairou J, Bui LC, Leger T, Lamouri A (2015) Parkinsonism-associated protein DJ-1/Park7 is a major protein deglycase that repairs methylglyoxal- and glyoxal-glycated cysteine, arginine, and lysine residues. J Biol Chem 290:1885-1897

Richarme G, Liu C, Mihoub M, Abdallah J, Leger T, Joly N, Liebart JC, Jurkunas UV, Nadal M, Bouloc P et al (2017) Guanine glycation repair by DJ-1/Park7 and its bacterial homologs. Science 357:208-211

Rinschen MM, Ivanisevic J, Giera M, Siuzdak G (2019) Identification of bioactive metabolites using activity metabolomics. Nat Rev Mol Cell Biol 20:353-367

Rydberg B, Lindahl T (1982) Nonenzymatic methylation of DNA by the intracellular methyl group donor S-adenosyl-L-methionine is a potentially mutagenic reaction. EMBO $J$ 1:211-216

Sanghvi VR, Leibold J, Mina M, Mohan P, Berishaj M, Li Z, Miele MM, Lailler N, Zhao C, de Stanchina E et al (2019) The oncogenic action of NRF2 depends on de-glycation by fructosamine-3-kinase. Cell 178:807-819

Schalkwijk CG, Stehouwer CDA (2020) Methylglyoxal, a highly reactive dicarbonyl compound, in diabetes, its vascular complications, and other age-related diseases. Physiol Rev 100:407461

Schumacker PT (2006) Reactive oxygen species in cancer cells: live by the sword, die by the sword. Cancer Cell 10:175-176

Shuck SC, Wuenschell GE, Termini JS (2018) Product studies and mechanistic analysis of the reaction of methylglyoxal with deoxyguanosine. Chem Res Toxicol 31:105-115

Shuker DE, Prevost V, Friesen MD, Lin D, Ohshima H, Bartsch H (1993) Urinary markers for measuring exposure to endogenous and exogenous alkylating agents and precursors. Environ Health Perspect 99:33-37

Singh R, Barden A, Mori T, Beilin L (2001) Advanced glycation endproducts: a review. Diabetologia 44:129-146

Spiro RG (2002) Protein glycosylation: nature, distribution, enzymatic formation, and disease implications of glycopeptide bonds. Glycobiology 12:43R-56R

Sun R, Fu L, Liu K, Tian C, Yang Y, Tallman KA, Porter NA, Liebler DC, Yang J (2017) Chemoproteomics reveals chemical diversity and dynamics of 4-oxo-2-nonenal modifications in cells. Mol Cell Proteomics 16:1789-1800

Suzuki A, Yamada R, Chang X, Tokuhiro S, Sawada T, Suzuki M, Nagasaki M, Nakayama-Hamada M, Kawaida R, Ono $M$ et al 
(2002) Functional haplotypes of PADI4, encoding citrullinating enzyme peptidylarginine deiminase 4 , are associated with rheumatoid arthritis. Nat Genet 34:395-402

Synold T, Xi B, Wuenschell GE, Tamae D, Figarola JL, Rahbar S, Termini $J$ (2008) Advanced glycation end products of DNA: quantification of N2-(1-Carboxyethyl)-2'-deoxyguanosine in biological samples by liquid chromatography electrospray ionization tandem mass spectrometry. Chem Res Toxicol 21:2148-2155

Szende B, Tyihák E (2010) Effect of formaldehyde on cell proliferation and death. Cell Biol Int 34:1273-1282

Szwergold BS, Howell S, Beisswenger PJ (2001) Human fructosamine-3-kinase: purification, sequencing, substrate specificity, and evidence of activity in vivo. Diabetes 50:2139-2147

Taira T, Saito Y, Niki T, Iguchi-Ariga SM, Takahashi K, Ariga H (2004) DJ-1 has a role in antioxidative stress to prevent cell death. EMBO Rep 5:213-218

Talasz H, Wasserer S, Puschendorf B (2002) Nonenzymatic glycation of histones in vitro and in vivo. J Cell Biochem 85:24-34

Tamae D, Lim P, Wuenschell GE, Termini J (2011) Mutagenesis and repair induced by the DNA advanced glycation end product N2-1(carboxyethyl)-2'-deoxyguanosine in human cells. Biochemistry 50:2321-2329

Teodorowicz M, Hendriks WH, Wichers HJ, Savelkoul HFJ (2018) Immunomodulation by Processed Animal Feed: the role of maillard reaction products and advanced glycation end-products (AGEs). Front Immunol 9:2088

Toyoda Y, Erkut C, Pan-Montojo F, Boland S, Stewart MP, Müller DJ, Wurst W, Hyman AA, Kurzchalia TV (2014) Products of the Parkinson's disease-related glyoxalase DJ-1, D-lactate and glycolate, support mitochondrial membrane potential and neuronal survival. Biol Open 3:777-784

Trerotola M, Relli V, Simeone P, Alberti S (2015) Epigenetic inheritance and the missing heritability. Hum Genomics 9:17

Tzika E, Dreker T, Imhof A (2018) Epigenetics and metabolism in health and disease. Front Genet 9:361

Van Laer K, Hamilton CJ, Messens J (2013) Low-molecular-weight thiols in thiol-disulfide exchange. Antioxid Redox Signal 18:16421653

Van Schaftingen E, Delpierre G, Collard F, Fortpied J, Gemayel R, Wiame E, Veiga-da-Cunha M (2007) Fructosamine 3-kinase and other enzymes involved in protein deglycation. Adv Enzyme Regul 47:261-269

Veiga da-Cunha M, Jacquemin P, Delpierre G, Godfraind C, Théate I, Vertommen D, Clotman F, Lemaigre F, Devuyst O, Van Schaftingen $E$ (2006) Increased protein glycation in fructosamine 3-kinase-deficient mice. Biochem J 399:257-264

Wagner GR, Hirschey MD (2014) Nonenzymatic protein acylation as a carbon stress regulated by sirtuin deacylases. Mol Cell 54:5-16

Wang Y, Wysocka J, Sayegh J, Lee YH, Perlin JR, Leonelli L, Sonbuchner LS, McDonald CH, Cook RG, Dou Y et al (2004) Human PAD4 regulates histone arginine methylation levels via demethylimination. Science 306:279-283

Wanner MJ, Zuidinga E, Tromp DS, Vilím J, Jørgensen SI, van Maarseveen JH (2020) Synthetic evidence of the Amadori-type alkylation of biogenic amines by the neurotoxic metabolite dopegal. J Org Chem 85:1202-1207
Wei B, Berning K, Quan C, Zhang YT (2017) Glycation of antibodies: Modification, methods and potential effects on biological functions. MAbs 9:586-594

Weng X, Gong J, Chen Y, Wu T, Wang F, Yang S, Yuan Y, Luo G, Chen K, Hu L et al (2020) Keth-seq for transcriptiome wide RNA structure mapping. Nat Chem Biol. https://doi.org/10.1038/ s41589-019-0459-3

Wilson MR, Jiang Y, Villalta PW, Stornetta A, Boudreau PD, Carrá A, Brennan CA, Chun E, Ngo L, Samson LD et al (2019) The human gut bacterial genotoxin colibactin alkylates DNA. Science 363: eaar7785

Wuenschell GE, Tamae D, Cercillieux A, Yamanaka R, Yu C, Termini $J(2010)$ Mutagenic potential of DNA glycation: miscoding by (R)and (S)-N2-(1-carboxyethyl)-2'-deoxyguanosine. Biochemistry 49:1814-1821

Xu Y, Chen X (2006) Glyoxalase II, a detoxifying enzyme of glycolysis byproduct methylglyoxal and a target of p63 and p73, is a pro-survival factor of the p53 family. J Biol Chem 281:2670226713

Xu H, Huang W, He QL, Zhao ZX, Zhang F, Wang R, Kang J, Tang GL (2012) Self-resistance to an antitumor antibiotic: a DNA glycosylase triggers the base-excision repair system in yatakemycin biosynthesis. Angew Chem Int Ed Engl 51:10532-10536

Xu L, Chen J, Gao J, Yu H, Yang P (2015) Crosstalk of homocysteinylation, methylation and acetylation on histone $\mathrm{H} 3$. Analyst 140:3057-3063

Zhang Z, Smith BA, Wang L, Brock A, Cho C, Schultz PG (2003) A new strategy for the site-specific modification of proteins in vivo. Biochemistry 42:6735-6746

Zhang DD, Lo SC, Cross JV, Templeton DJ, Hannink M (2004) Keap1 is a redox-regulated substrate adaptor protein for a Cul3dependent ubiquitin ligase complex. Mol Cell Biol 24:1094110953

Zhang Q, Bai B, Mei X, Wan C, Cao H, Li Dan, Wang S, Zhang M, Wang Z, Wu J et al (2018) Elevated H3K79 homocysteinylation causes abnormal gene expression during neural development and subsequent neural tube defects. Nat Commun 9:3436

Zhang D, Tang Z, Huang H, Zhou G, Cui C, Weng Y, Liu W, Kim S, Lee S, Perez-Neut $M$ et al (2019) Metabolic regulation of gene expression by histone lactylation. Nature 574:575-580

Zheng Q, Prescott NA, Maksimovic I, David Y (2019a) (De)Toxifying the epigenetic code. Chem Res Toxicol 32:796-807

Zheng Q, Omans ND, Leicher R, Osunsade A, Agustinus AS, FinkinGroner E, D'Ambrosio H, Liu B, Chandarlapaty S, Liu S et al (2019b) Reversible histone glycation is associated with diseaserelated changes in chromatin architecture. Nat Commun 10:1289

Zheng Q, Osunsade A, David Y (2019) Protein arginine deiminase 4 antagonizes methylglyoxal-induced histone glycation. bioRxiv doi:10.1101/826818

Zheng Q, Maksimovic I, Upad A, Guber D, David Y (2020) Synthesis of an alkynyl methylglyoxal probe to investigate nonenzymatic histone glycation. J Org Chem 85:1691-1697

Zhu Y, Snooks H, Sang S (2018) Complexity of advanced glycation end products in foods: Where are we now? J Agric Food Chem 66:1325-1329 